Association for Information Systems AIS Electronic Library (AISeL)

Research-in-Progress Papers

ECIS 2019 Proceedings

5-15-2019

\title{
TOWARDS A UNIFYING FRAMEWORKFOR DESIGN AND ACTION-ORIENTED IS RESEARCH
}

Andreas Drechsler

Victoria University of Wellington, andreas.drechsler@vuw.ac.nz

Follow this and additional works at: https://aisel.aisnet.org/ecis2019_rip

\section{Recommended Citation}

Drechsler, Andreas, (2019). "TOWARDS A UNIFYING FRAMEWORK FOR DESIGN AND ACTION-ORIENTED IS RESEARCH". In Proceedings of the 27th European Conference on Information Systems (ECIS), Stockholm \& Uppsala, Sweden, June 8-14, 2019. ISBN 978-1-7336325-0-8 Research-in-Progress Papers.

https://aisel.aisnet.org/ecis2019_rip/41

This material is brought to you by the ECIS 2019 Proceedings at AIS Electronic Library (AISeL). It has been accepted for inclusion in Research-inProgress Papers by an authorized administrator of AIS Electronic Library (AISeL). For more information, please contact elibrary@aisnet.org. 


\title{
TOWARDS A UNIFYING FRAMEWORK FOR DESIGN AND ACTION-ORIENTED IS RESEARCH
}

\author{
Research in Progress
}

\begin{abstract}
Andreas Drechsler, Victoria University of Wellington, Wellington, New Zealand, andreas.drechsler@vuw.ac.nz
\end{abstract}

\begin{abstract}
The paper presents an initial version of a framework that illustrates the high-level similarities across several common forms of design or action-oriented IS research, such as design science research (DSR) focused on developing meta-artefacts or artefact instances, action design research (ADR), or canonical action research (CAR). The paper further illustrates how these forms of design or action-oriented IS research emphasise different forms of knowledge utilisation and contribution potentials, the design of different solution entities, and pursue different paths towards achieving real-world impact. Researchers can utilise the framework to guide their choice of a research approach at the start of the project or become aware of yet untapped knowledge contribution potentials in their chosen one. Further research can expand the scope of the frameworks beyond DSR, ADR and CAR, or draw on the framework to investigate the potential of leveraging good research practices or research outcomes developed for/by one form of research for the other forms.
\end{abstract}

Keywords: design research; action design research; action research; research impact; knowledge utilisation; knowledge contribution 


\section{Introduction}

Over the recent decade, research approaches that follow the paradigm - in the true Kuhnian sense of the word (Hassan and Mingers, 2018) - of designing potential solutions to real-world problems or having an actual impact on the real world have become increasingly popular in IS (Rai, 2017). The most common approaches in the general IS literature that follow this overarching paradigm are design science research (DSR) (Gregor and Hevner, 2013; Hevner et al., 2004), action design research (ADR) (Sein et al., 2011), and canonical action research (CAR) (Davison et al., 2004). While there are several other approaches with the same paradigmatic goal (see also the final section), these three established and quite popular approaches are chosen as a parsimonious selection for the scope of this paper, in order to stay within the confines of the space available.

Each of these action, solution or impact-oriented research approaches has developed its own terminologies, practices, and standards, limiting the discourse between researchers using them. There have been a number of papers highlighting the differences between, for instance, design and action research (Iivari and Venable, 2009; Järvinen, 2007; Maccani et al., 2015). However, these papers ultimately give little guidance to researchers wishing to embark on a new research endeavour with meaningful impact (such as developing a solution to an organisational or societal problem) regarding which of these approaches they should select for the dual purpose of achieving the highest possible real-world impact as well as academic impact (in the sense of making substantial knowledge contributions).

Following a recent call to go beyond established labels in characterising IS research traditions (Rai, 2018), this paper has the goal of providing a first attempt of a unified outcome-oriented view across the different common forms of design, action or impact-oriented research mentioned above. In-line with the dual nature of the underlying paradigm, both real-world impact outcomes and academic knowledge outcomes are considered.

It is acknowledged that the covered IS research approaches may rest on differing onto-epistemological assumptions and embody differing values. However, the framework highlights that an abstraction over these assumptions can nevertheless illustrate which entities these approaches focus on, how they produce impact, and how they draw on and can contribute to the knowledge bases. Simultaneously, the resulting individual knowledge contributions of the different approaches or the methods and techniques they rely on or utilise may, in fact, be incommensurable - but this aspect is outside this paper's scope and requires further investigation.

Section 2 gives an overview of the overall framework representing such a unified view. Section 3 illustrates how the selected research approaches emphasise different parts of the framework. Researchers can let these different emphases guide their decision towards making the initial choice of one research approach over the other, depending on which emphases seem to be the most suitable for the research challenge they face, or where their main contribution interests lie. The paper concludes with a fourth section, which discusses some arising implications and gives an outlook towards future research.

\section{$2 \quad$ A Unifying Framework for Design and Action-oriented IS Research}

Table 1 shows how IS research approaches such as DSR (Gregor and Hevner, 2013; Hevner et al., 2004), ADR (Sein et al., 2011), or CAR (Davison et al., 2004) have several aspects in common, but sometimes use different terminologies. Figure 1 expands this perspective and shows a general framework for IS research approaches that follow the paradigmatic goal of bringing about design, action, change, or impact. The next section will illustrate how specific forms of the three aforementioned research approaches (DSR, ADR, CAR) utilize different parts of Figure 1, and that no approach covers all parts of Figure 1 simultaneously. 


\begin{tabular}{|c|c|c|c|}
\hline & DSR & ADR & CAR \\
\hline Trigger & $\begin{array}{l}\text { Real-world (class of) goals or } \\
\text { problems (technical and/or } \\
\text { organizational) }\end{array}$ & $\begin{array}{l}\text { (Class of) field problems as } \\
\text { inspiration for knowledge cre- } \\
\text { ation }\end{array}$ & Organizational problems \\
\hline $\begin{array}{l}\text { Research } \\
\text { process }\end{array}$ & $\begin{array}{l}\text { Rigour, design, and relevance } \\
\text { cycles }\end{array}$ & $\begin{array}{l}\text { IT-dominant or organization- } \\
\text { dominant BIR cycles (build- } \\
\text { ing, intervention, evaluation) }\end{array}$ & $\begin{array}{l}\text { Cyclical process model } \\
\text { (diagnosis, action plan- } \\
\text { ning, intervention, evalua- } \\
\text { tion, reflection) }\end{array}$ \\
\hline Outcomes & $\begin{array}{l}\text { (Meta-)artefacts: technical } \\
\text { and/or organizational } \\
\text { constructs, models, methods, in- } \\
\text { stantiations (and other forms) }\end{array}$ & $\begin{array}{l}\text { Ensemble artefacts as emer- } \\
\text { gent knowledge to be applied } \\
\text { to the (class of) field problems } \\
\text { to address / solve them }\end{array}$ & $\begin{array}{l}\text { Interventions in organiza- } \\
\text { tions (change through } \\
\text { action) }\end{array}$ \\
\hline $\begin{array}{l}\text { Roles of } \\
\text { knowledge }\end{array}$ & $\begin{array}{l}\text { Knowledge informs design, } \\
\text { design and evaluation outcomes } \\
\text { contribute to knowledge }\end{array}$ & $\begin{array}{l}\text { Knowledge informs artefact } \\
\text { development and interven- } \\
\text { tions, generalised outcomes as } \\
\text { formalised learning }\end{array}$ & $\begin{array}{l}\text { Theory guides interven- } \\
\text { tions and interventions } \\
\text { help develop theory (learn- } \\
\text { ing through reflection) }\end{array}$ \\
\hline
\end{tabular}

Table 1. Similarities and differences between the covered three IS research approaches

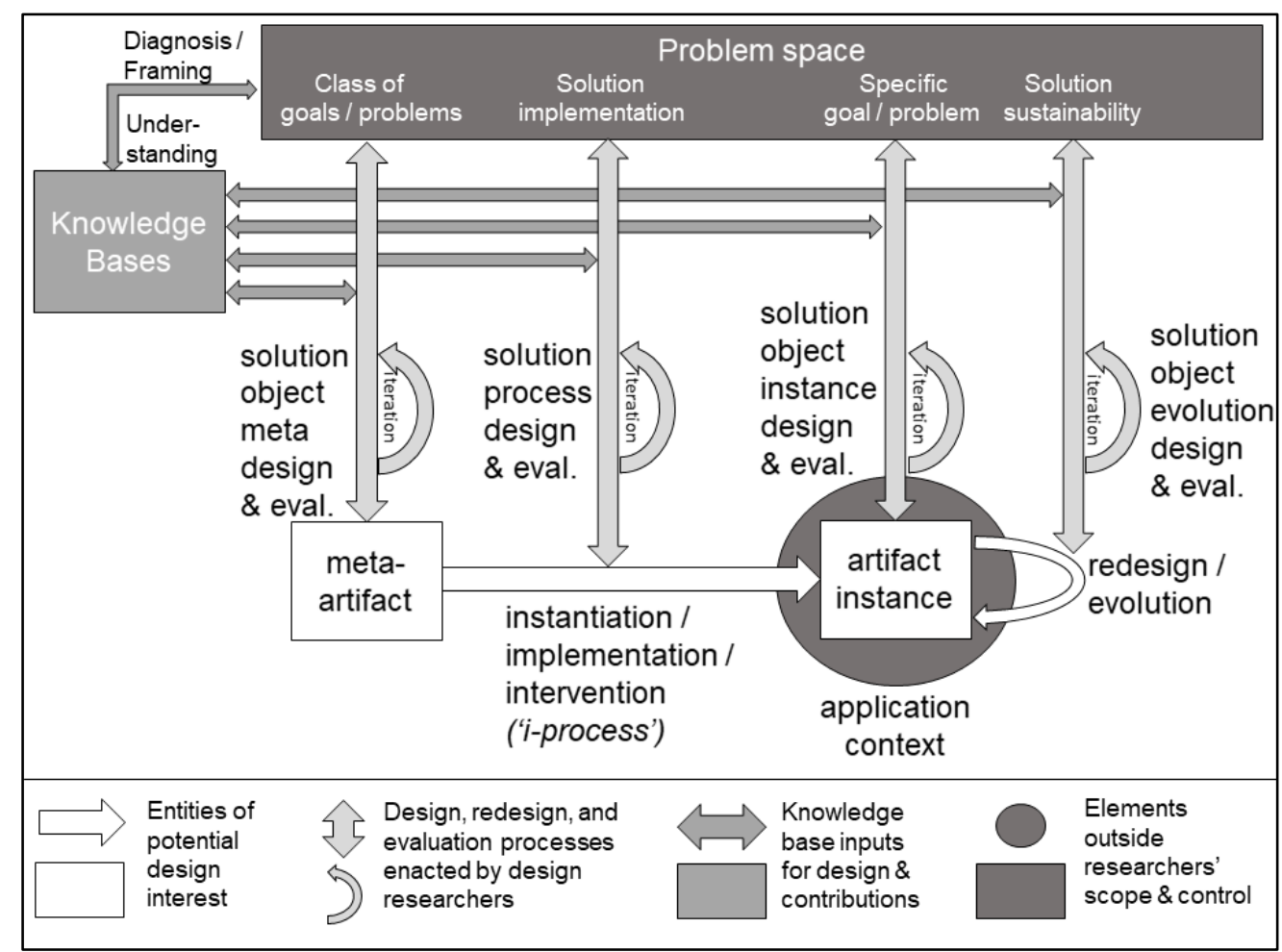

Figure 1: General framework of design, action and impact-oriented IS research

All approaches have in common that they address one or more issues within a problem space (represented by Figure 1's the dark box shape at the top). An issue can be 1) a general class of real-world goals or problems, 2) a particular instance of such a goal or problem, 3) the challenge to implement a designed general solution within a specific context or to intervene in a specific context with the goal to bring forth any solution, or 4) that changes within the context may jeopardize an established solution's effectiveness over time. This problem space lies outside of the researcher's control, as does the application context, i.e. the place where the outcome (the developed solution or intervention) is going to be applied.

Table and Figure 1 further illustrate that there are four different entities (represented by the white boxes or arrows) across the different design-oriented IS research approaches that can be of research interest (Drechsler and Hevner, 2018). Despite the criticism directed at the artefact term in the IS context (Alter, 
2015), we will use the terms meta-artefact and artefact instance throughout this paper to denote the abstract and the concrete solution objects among these design entities of interest. By doing so, we conform to the established terminology in the sciences of the artificial and IS DSR (Drechsler and Hevner, 2018; Gregor and Hevner, 2013; Iivari, 2016; Simon, 1996). In contrast, policy-oriented research, for instance, would call the design entity of interest 'policy' and not artefact (Majchrzak and Markus, 2014).

Meta-artefacts are artefacts that lead to the development of other artefacts. Meta-artefacts comprise abstract or mid-range artefacts (e.g., an ERP system or a software development (SD) process model) that need to be instantiated and introduced to specific local application contexts (Gregor and Hevner 2013). Meta-artefacts also include artefacts that generate, or change, totally different artefacts (Iivari, 2003, 2015) - for example, using a process model to introduce a formal software development process into an organization that has not yet employed any formal software development processes. An artefact instance is a local or situated artefact within a specific application context. Meta-artefacts constitute more abstract (nomothetic) knowledge about technology, while knowledge about artefact instances constitutes local (idiographic) knowledge (Baskerville et al., 2015). Note that meta-artefacts and artefact instances represent merely two archetypical points on a continuum of artefacts that are less or more tailored to be applicable to and useful in less or more specific contexts. The nature of meta-artefacts and artefact instances can also be quite varied; they can be - or comprised of - constructs, models, and/or methods, but can also take many other shapes as well (Drechsler and Hevner, 2018; Hevner et al., 2004).

A third design entity of potential interest is the instantiation / implementation / intervention process (or i-process for short) to intervene in an application context, for instance, by instantiating, adapting, and introducing a meta-artefact into a specific context (Drechsler and Hevner, 2018). Here, canonical action research focuses on organizational or social interventions to bring forth solutions instead of focusing on the design of solution objects (Davison et al., 2004). A final design entity of potential interest is the process to redesign / evolve a solution instance to retain or enhance its utility in the light of changing requirements or contexts (Gill and Hevner, 2013).

All four design entities of interest have corresponding (re)design and evaluation processes (the light grey arrows in Figure 1). As denoted by the curved light grey arrows in Figure 1, these (re)design and evaluation activities often have an iterative or cyclical nature. Note that all these design processes take place within design systems with social (e.g., designers) and technical (e.g., design tools) components (Drechsler and Hevner, 2018; Gill and Hevner, 2013).

In turn, all four processes can draw on different forms of human knowledge (the medium gray box in Figure 1) to inform the design, intervention, and evaluation activities as well as the designs itself, and all four processes can contribute different forms of knowledge back to the human knowledge bases, depending on the outcome of the respective processes (the medium gray-coloured dual arrows in Figure 1 ). On the highest level, knowledge economics distinguishes between $\Omega$-knowledge (comprising descriptive and explanatory knowledge) and different forms of applicable (or prescriptive) knowledge or $\Lambda$-knowledge (Gregor and Hevner, 2013; Mokyr, 2004). Within $\Lambda$-knowledge, there is a further distinction to be made between solution entities such as artefacts or interventions on the one hand and artefactindependent knowledge for action on the other hand (Drechsler and Hevner, 2018). Improving the understanding of the problem space is a further contribution to the knowledge base outside of designfocused activities. In turn, such an enhanced understanding can improve the actual problem diagnosis before the design or action-oriented activities commence. Moreover, the process of framing and scoping of a problem for a design or action-oriented research endeavour depends on a refined understanding of the problem's nature and context. Subsequently, a real-world intervention can increase our understanding of the real-world through investigating the effects of interventions or artefact implementations.

\section{Representing different forms of design, action or impact-ori- ented IS research}

In this section, we illustrate how the most common forms of design or action-oriented IS research draw on the elements of Figure 1 in a different way. Please note that all depictions are archetypical, simplified, 
and serve illustrative purposes only. Moreover, considering the ability of a solution to evolve over time to foster sustained utility is recommended, but optional. The two IS DSR strategies (3.1/3.2 and 3.3) are based on Iivari (2015). Artificial versus natural evaluation is discussed in Venable et al. (2016). Figure 2 shows the legend used for all subsequent figures.

\begin{tabular}{|llll}
\hline $\begin{array}{l}\text { Entities of } \\
\text { potential } \\
\text { design } \\
\text { interest }\end{array}$ & $\begin{array}{l}\text { Design, redesign, and } \\
\text { evaluation processes } \\
\text { enacted by design } \\
\text { researchers }\end{array}$ & $\begin{array}{l}\text { Knowledge } \\
\text { base inputs } \\
\text { for design \& } \\
\text { contributions }\end{array}$ & $\begin{array}{l}\text { Elements } \\
\text { outside } \\
\text { researchers' } \\
\text { scope \& control }\end{array}$
\end{tabular}

Figure 2: Legend for Figures 3-7

\subsection{IS DSR - Strategy 1 (Artificial Evaluation)}

The first IS DSR strategy that Iivari (2015) distinguishes is to start with a meta-artefact that addresses a class of real-world problems. If the evaluation is limited to an artificial one (e.g., a formal proof, a theoretical analysis, a lab experiment, or a simulation) (Venable et al., 2016), then no instantiation is needed or desired within a research project. The impact in this case is solely an academic one, and may lead to a subsequent research project that applies the potential meta-solution to an actual instance of a problem, in order to achieve a real-world impact. Figure 3 shows the elements of the overall framework of Figure 1 in this form of DSR, illustrating its limited knowledge contribution potential.

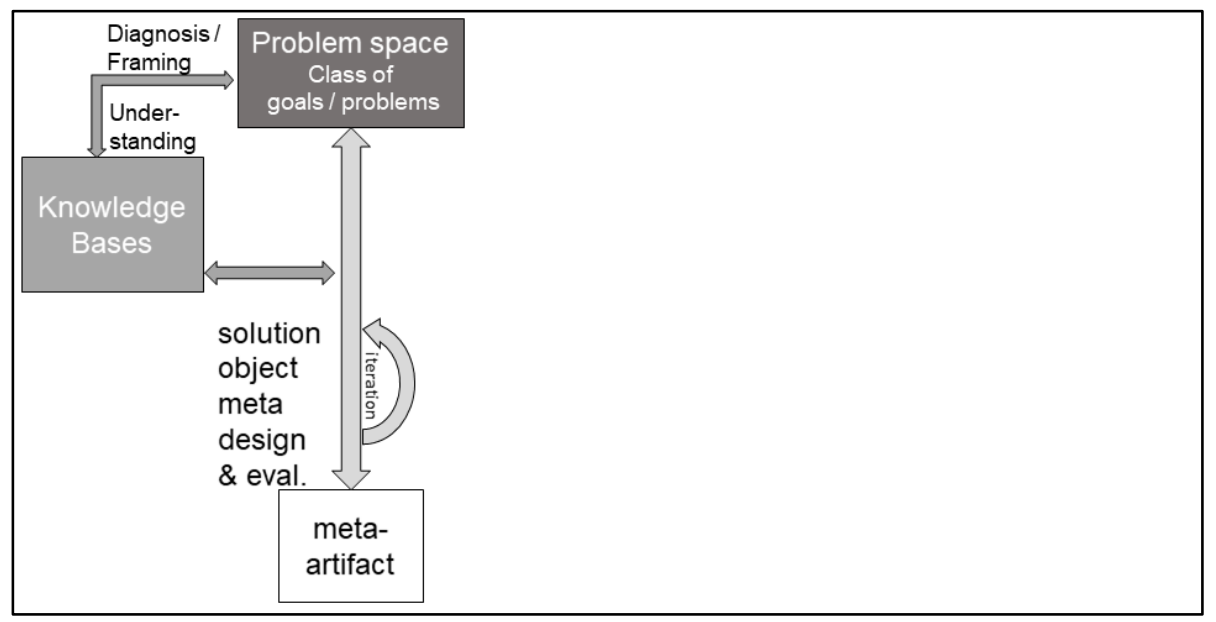

Figure 3: DSR Strategy 1 with artificial evaluation (= no instantiation)

\subsection{IS DSR - Strategy 1 (Naturalistic Evaluation)}

In case the DSR strategy 1 is combined with a naturalistic (i.e. real-world) evaluation, the developed meta-artefact needs to be instantiated in an actual application context (one or more organisations or parts of society). Since this means a change to the affected parts of an organisation or society, the process of instantiating and implementing the artefact into its application context also requires attention (van Aken, 2004). It is up to the researchers' choice to include this instantiation / implementation process into the focal scope of their research or treat it as a necessity on the side to achieve the necessary impact to conduct the naturalistic evaluation. Figure 4 shows the elements of the framework that are of particular interest in this case (with a potentially varying emphasis on the 'implementation' arrow).

Figure 4 highlights that, compared to Figure 3, the existing knowledge bases become of greater interest to inform not only the initial design, but also the instantiation/implementation process and predict the impact of the artefact instance in its application context. Moreover, the whole issue of the solution sustainability or artefact fitness arises (Gill and Hevner, 2013) - which, again, may or may not be the focal interest of the researchers involved. Consequently, all these four aspects (the meta-artefact, its instanti- 


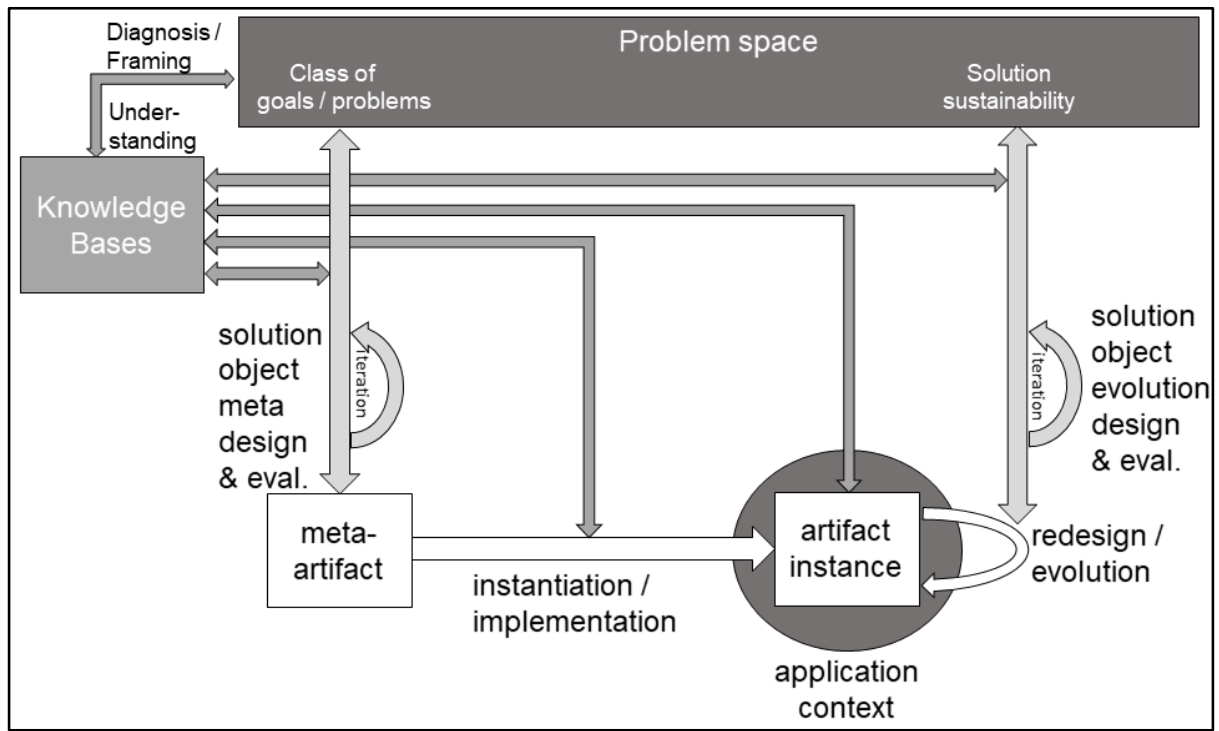

Figure 4: DSR Strategy 1 with a naturalistic evaluation of an artefact instance

ation / implementation, the impact of the artefact instance to the application context and its effectiveness, and its evolution and sustainability) have their own knowledge contribution potential.

\subsection{IS DSR - Strategy 2 / Action Design Research}

Another DSR strategy is to start with a situated artefact or artefact instance as a context-specific solution and to try to abstract from the context in a subsequent step (Iivari, 2015). Action design research (Sein et al., 2011) has a similar goal, with an additional emphasis on the interventions in the application context to sustainably introduce the built artefact instance into the context and achieve the desired impact. Figure 5 visualises the relevant aspects of the framework for this research approach.

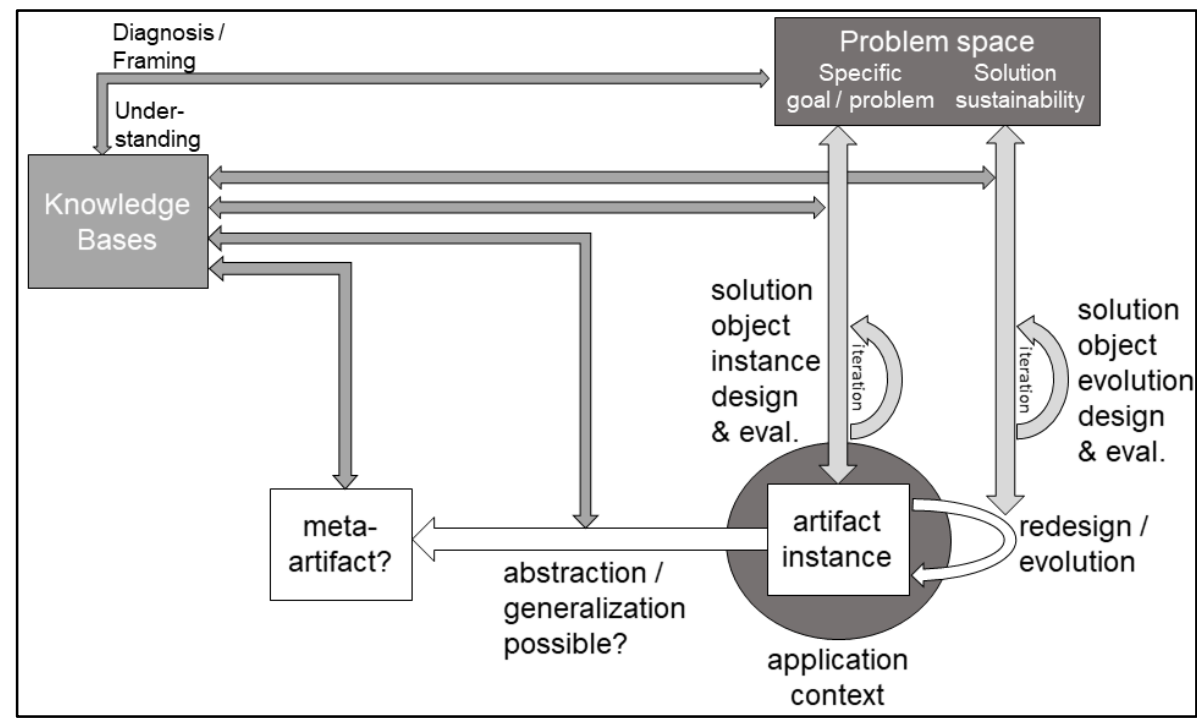

Figure 5: DSR Strategy 2 or Action Design Research with no initial meta-artefact design

Compared with Figure 4, Figure 5 illustrates that the general knowledge contribution potential of this DSR strategy and ADR is similar to the other DSR strategy if coupled with a naturalistic evaluation, despite the shift in emphasis towards the specific and not the abstract problem space. It can be expected, however, that the nature of the individual knowledge contributions made through the dark grey arrows would be of a different nature compared to the knowledge contributions made by following the DSR 
strategy 1. Moreover, not all four knowledge contribution directions may be emphasised similarly in a DSR versus an ADR project.

There may also be ADR projects that where the solution process constitutes the main research interest instead of the actual solution object (and this solution object would then be an emergent outcome of the solution process). Figure 6 shows how such an ADR project would look like in the framework.

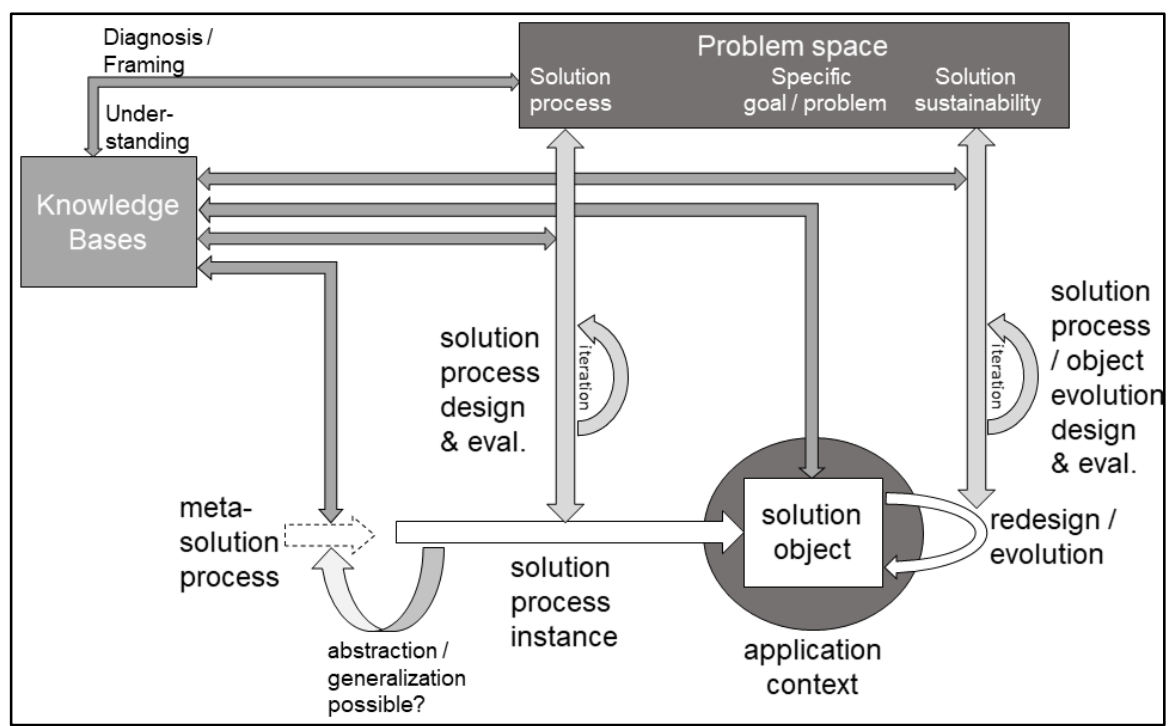

Figure 6: Action Design Research with a focus on the solution process instead of the solution object

\subsection{Canonical Action Research}

The final research approach covered in this paper is canonical action research (CAR) (Davison et al., 2004) as one selected representative of many different types of action research (AR). In a nutshell, CAR differs from the previous approaches that the emphasis does not lie on static artefacts as solution entities, but dynamic or processual organizational interventions to bring about an intended organizational change. Moreover, the academic goal of a theoretical contribution is formulated more strongly than it is in the case of DSR or ADR, and the same arguably applies to the necessity of a strong theoretical framework informing the intervention.

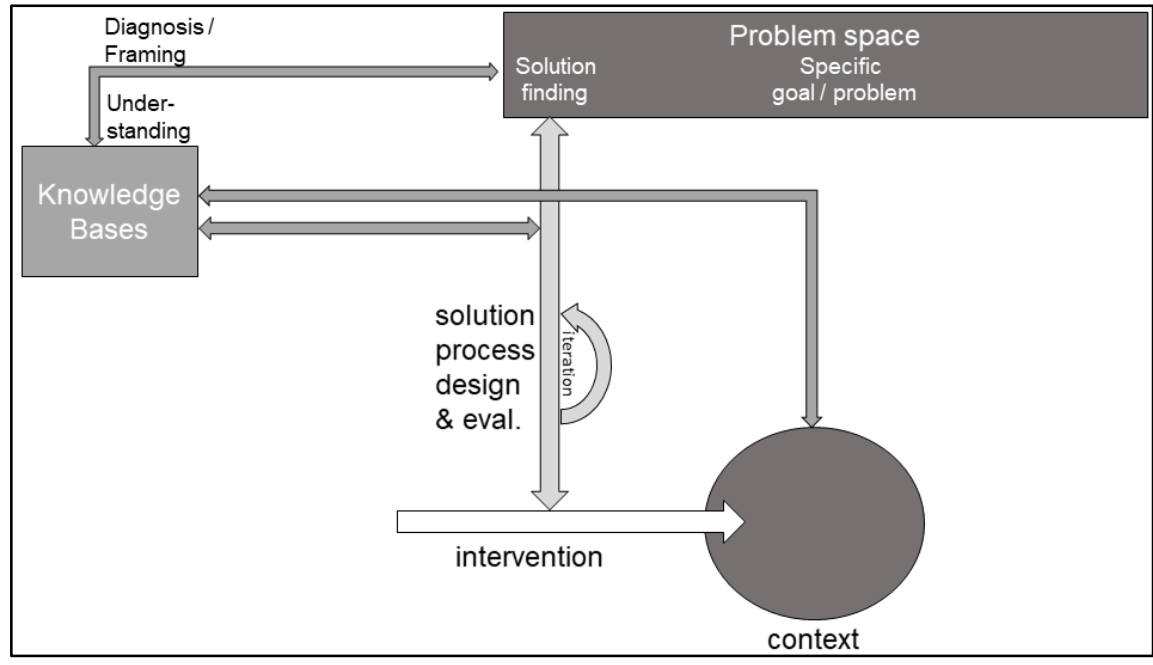

Figure 7: Canonical Action Research (focus on the intervention instead of on artefacts)

Figure 7 therefore emphasises the intervention into an organisational context as the single key solution entity of interest. Note that the reduced number of arrows indicating the potential for knowledge contributions does not mean that the overall knowledge contribution potential of CAR is inferior to DSR and 
ADR (and the current state of CAR articles indicate quite the contrary). It merely means that the paths towards knowledge contributions are more focused than for DSR and ADR.

\section{Discussion, Conclusion, Outlook}

This paper presented a framework that captures key characteristics of design or action-oriented research approaches and illustrated how parts of the framework apply to common forms of design or actionoriented IS research. Due to the shift away from onto-epistemological or other paradigmatic distinctions of differing characteristics (Hassan and Mingers, 2018) among the covered research approaches, the framework shown in Figure 1 is a first attempt to highlight the commonalities and varieties of the covered research approaches and to go beyond established labels (Rai, 2018) by highlighting how the different approaches achieve real-world impact and academic impact (knowledge contributions).

Researchers can utilise the framework to guide their choice of a research approach at the start of the project. For instance, a researcher may first decide that the solution object is of higher interest than the i-process for them to reach their research goal and therefore exclude CAR as a research approach. Based on the nature of the intended application context they could then decide that it would be more promising to focus on the actual solution object instance first and generalize later. This would indicate that ADR may be the more suitable research approach than meta-artefact-oriented DSR. Researchers can also draw on the framework to become aware of yet untapped knowledge contribution potential in their chosen one when they discover that they did not truly exploit all of the 'dark grey' arrows leading back to the knowledge base.

Further research can extend the perspective taken in this paper to other forms of impact-oriented research such as management DSR (van Aken and Romme, 2009), evidence-based management (van Aken and Romme, 2012), engaged scholarship (Mathiassen and Nielsen, 2008; Van de Ven, 2007), organizational design (Burton et al., 2015, 1998), the socio-technical approach (Mumford, 2006), the soft systems methodology (Checkland, 1999), participatory design (Stahl, 2014), policy research (Majchrzak and Markus, 2014), or other forms of action research beyond CAR. Such extensions may not only refine the framework further to gain a more extended perspective on aspects of impact-oriented research. It would also enable researchers to have a foundation to draw on good research practices developed in any of the forms of impact-oriented research, provided that there are not insurmountable paradigmatic incommensurabilities between the source and the destination research approach for such a transfer of good research practice. Another angle for future research could be to design and evaluate a more formalised decision framework for researchers to guide their decision on which impact-oriented research approach to choose, based on the specifics of a given research goal, problem, and context.

\section{References}

Aken, Joan E. van. (2004). "Management research based on the paradigm of the design sciences: the quest for field-tested and grounded technological rules." Journal of management studies 41 (2), 219-246.

Aken, Joan Ernst van, and Romme, G. (2009). "Reinventing the future: adding design science to the repertoire of organization and management studies." Organization Management Journal 6 (1), $5-12$.

Alter, S. (2015). "The concept of 'IT artifact' has outlived its usefulness and should be retired now." Information Systems Journal 25 (1), 47-60.

Baskerville, R. L., Kaul, M., and Storey, V. C. (2015). "Genres of inquiry in design-science research: Justification and evaluation of knowledge production.” Mis Quarterly 39 (3), 541-564.

Burton, R. M., Obel, B., and Hla akonsson, D. D. (2015). Organizational design: A step-by-step approach. Cambridge University Press. 
Burton, R. M., Obel, B., Hunter, S., Søndergaard, M., and Døjbak, D. (1998). Strategic organizational diagnosis and design: Developing theory for application. Springer Science \& Business Media.

Checkland, P. (1999). Soft systems methodology: a 30-year retrospective. Chichester; New York: John Wiley.

Davison, R., Martinsons, M. G., and Kock, N. (2004). "Principles of canonical action research." Information Systems Journal 14 (1), 65-86.

Drechsler, A., and Hevner, A. R. (2018). "Utilizing, Producing, and Contributing Design Knowledge in DSR Projects." In Designing for a Digital and Globalized World (pp. 82-97). Springer, Cham.

Gill, T. G., and Hevner, A. R. (2013). "A Fitness-Utility Model for Design Science Research.” ACM Transactions on Management Information Systems 4 (2), 5:1-5:24.

Gregor, S., and Hevner, A. R. (2013). "Positioning and Presenting Design Science Research for Maximum Impact.” MIS Quarterly 37 (2), 337-A6.

Hassan, N., and Mingers, J. (2018). "Reinterpreting the Kuhnian Paradigm in Information Systems." Journal of the Association for Information Systems 19 (7), 568-599.

Hevner, A., March, S. T., Park, J., and Ram, S. (2004). "Design Science in Information Systems Research." MIS Quarterly 28 (1), 75-105.

Iivari, J. (2003). "The IS Core - VII: Towards Information Systems as a Science of Meta-Artifacts." Communications of the Association for Information Systems 12 (1), Article 37.

Iivari, J. (2015). "Distinguishing and contrasting two strategies for design science research." European Journal of Information Systems 24 (1), 107-115.

Iivari, J. (2016). "Information system artefact or information system application: that is the question." Information Systems Journal n/a-n/a.

Iivari, J., and Venable, J. (2009). "Action Research and Design Science Research - Seemingly similar but decisively dissimilar." Proceedings of the ECIS 2009 conference, Verona.

Järvinen, P. (2007). “Action research is similar to design science." Quality \& Quantity 41 (1), 37-54.

Maccani, G., Donnellan, B., and Helfert, M. (2015). "Action Design Research: A Comparison with Canonical Action Research and Design Science.” In B. Donnellan, R. Gleasure, M. Helfert, J. Kenneally, M. Rothenberger, M. Chiarini Tremblay, ... R. Winter (Eds.), At the Vanguard of Design Science: First Impressions and Early Findings from Ongoing Research (pp. 69-76). Dublin, Ireland: DESRIST.

Majchrzak, A., and Markus, M. L. (2014). Methods for Policy Research: Taking Socially Responsible Action. 1 Oliver's Yard, 55 City Road London EC1Y 1SP: SAGE Publications, Ltd.

Mathiassen, L., and Nielsen, P. (2008). "Engaged Scholarship in IS Research.” Scandinavian Journal of Information Systems 20 (2), 3-20.

Mokyr, J. (2004). The Gifts of Athena: Historical Origins of the Knowledge Economy. Princeton, NJ: Princeton University Press.

Mumford, E. (2006). "The story of socio-technical design: Reflections on its successes, failures and potential.” Information Systems Journal 16 (4), 317-342.

Rai, A. (2017). "Editor's Comments: Diversity of Design Science Research.” Management Information Systems Quarterly 41 (1), iii-Xviii.

Rai, A. (2018). "Editor's Comments: Beyond Outdated Labels: The Blending of IS Research Traditions." Management Information Systems Quarterly 42 (1). 
Sein, M., Henfridsson, O., Purao, S., Rossi, M., and Lindgren, R. (2011). "Action Design Research.” MIS Quarterly 35 (1), 37-56.

Simon, H. A. (1996). The Sciences of the Artificial (3. Aufl.). Cambridge, Massachusetts: MIT Press.

Stahl, B. C. (2014). "Participatory design as ethical practice - concepts, reality and conditions." Journal of Information, Communication \& Ethics in Society 12 (1), 10-13.

van Aken, Joan Ernst, and Romme, A. G. L. (2012). "A Design Science Approach to Evidence-Based Management." In D. M. Rosseau (Ed.), The Oxford Handbook of Evidence-Based Management (pp. 43-61). New York: Oxford University Press.

Van de Ven, A. H. (2007). Engaged Scholarship: A Guide for Organizational and Social Research. New York: Oxford University Press.

Venable, J., Pries-Heje, J., and Baskerville, R. (2016). "FEDS: a Framework for Evaluation in Design Science Research.” European Journal of Information Systems 25 (1), 77-89. 